\title{
Interweaving categories: Styles, paradigms, and models
}

\author{
Rasmus Grønfeldt Winther \\ Philosophy Department, University of California (Santa Cruz), United States
}

Biocomplexity Center, Niels Bohr Institute, University of Copenhagen, Denmark

\section{A R T I C L E I N F O}

\section{Article history:}

Available online $\mathrm{xxxx}$

\section{Keywords:}

Styles of scientific research

Paradigms

Models

Realization

Systematics

Taxonomy

Trading zone

Scientific practice

Pluralism

Realism

Methodology

\begin{abstract}
A B S T R A C T
Analytical categories of scientific cultures have typically been used both exclusively and universally. For instance, when styles of scientific research are employed in attempts to understand and narrate science, styles alone are usually employed. This article is a thought experiment in interweaving categories. What would happen if rather than employ a single category, we instead investigated several categories simultaneously? What would we learn about the practices and theories, the agents and materials, and the political-technological impact of science if we analyzed and applied styles (à la Hacking and Crombie), paradigms (à la Kuhn), and models (à la van Fraassen and Cartwright) simultaneously? I address these questions in general and for a specific case study: a brief history of systematics.
\end{abstract}

() 2012 Elsevier Ltd. All rights reserved.

When citing this paper, please use the full journal title Studies in History and Philosophy of Science

\section{Introduction}

Analytical categories of scientific cultures have typically been used both exclusively and universally. For instance, when styles of scientific research are employed in attempts to understand and narrate science, styles alone are usually employed. This is also true for other important and influential categories used by the historian, philosopher, sociologist, and anthropologist of science: Kuhn's paradigms, Lakatos' research programmes, Laudan's research traditions, Holton's themata, and Foucault's epistemes. ${ }^{1}$ If we believe that our single category is the only correct (or relevant) one, or that all other categories simply cross-cut ours and can therefore be ignored without analytical loss, then we seem to be justified in using only our category. ${ }^{2}$ Although the details of the investigations vary tremendously, what is shared here is a belief in the single focal category's methodological and philosophical superiority, and a yearning for a universalized historico-sociological narrative.

This article is a thought experiment in interweaving categories. What would happen if instead of using only one category, we investigated several categories simultaneously? Put differently, what would we learn about the practices and theories, the agents and materials, and the political-technological impact of science if we analyzed and applied styles (à la Hacking and Crombie), paradigms (à la Kuhn), and models (à la van Fraassen and Cartwright) simultaneously?

In order to make up for a missed opportunity in the philosophy of science, this article is structured as follows. In three separate sections, I present the standard philosophy of science of styles

E-mail address: rgw@ucsc.edu

URL: http://www.rgwinther.com

1 All of these categories are subject to the general critiques of X (provided by Y): "conceptual schemes" (Davidson, 1973), "frameworks" (Popper, 1996), and

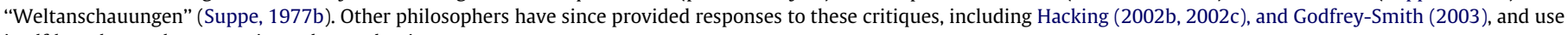
itself has shown the categories to be productive.

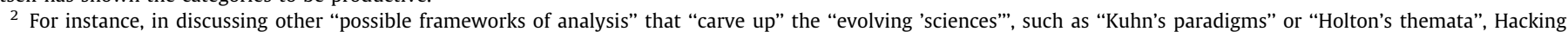

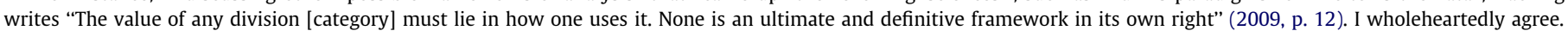

0039-3681/\$ - see front matter (c) 2012 Elsevier Ltd. All rights reserved.

http://dx.doi.org/10.1016/j.shpsa.2012.07.005 
(section 2), paradigms (section 3), and models (section 4). I then turn to a philosophical analysis of the dynamics of interweaving (section 5). Finally, a brief history of systematics (section 6), exemplifies interweaving categories, and the latter (philosophy) illuminates the former (history). I now provide a brief synopsis of each section, clustering together the first three.

Styles, models, and paradigms originate in projects that are constructive and critical. Their respective creators each suggested both a category with an internal structure and dynamics and a constructive analysis of science. Kuhn, for example, suggested both the category of a paradigm and an analysis of science as the serial replacement of paradigms (Aristotelian, Newtonian, quantum mechanical, Einsteinian, and so forth). Interestingly, the creators of each of the categories I investigate were criticizing and taking issue with a variety of perspectives in the philosophy of science: the Syntactic View, Methodological Universalists (e.g., Popper), and/or Historical Relativists (e.g., Late Feyerabend, Kusch, 2010).

Consider a heuristic image of the relationships among the three chosen categories: models are nested within (and guided by/realize) paradigms which, in turn, are nested within (and guided by/realize) styles. This picture is a useful start, even if it is also a false and overly simplified idealization. This hierarchical image entails that properties and parts of the upper category (e.g., styles) are inherited by the lower category (e.g., paradigms), and that categories above guide and are realized in the categories below. The structure of actual scientific practice is of course more complex. Multiple realization among category levels, and hybridization within a level, are commonplace, and new parts and aspects sometimes emerge at lower-level categories.

Case studies matter. In order to understand the interweaving of categories, I present a brief history of systematics. Systematics is the trading zone (Galison, 1997; see Winther, in press) of taxonomy and classification (i.e., pattern) on the one hand, and phylogeny and evolutionary theory (i.e., process) on the other. My history highlights a handful of figures: Aristotle, Linnaeus, Darwin, Willi Hennig, and Cavalli-Sforza and Edwards qua collaborators. In terms of representations of the natural system and practices for reconstructing it, I explore three models: the Great Chain of Being, the Tree of Life, and the Network of Life (e.g., Hull, 1988; Mishler, 2009; Rieppel, 1988; Rieppel, 2010). Approaching the history of systematics as an interweaving of styles, paradigms, and models allows us to see the content, relevance, and development of systematics in a new and refreshing light.

This article is located in an Ian Hacking festschrift. My debts to Hacking's work are many. This paper effectively explores the three themes of scientific practice, pluralism, and realism, with an overarching fourth theme of styles. Hacking has defended each of these insightfully and tirelessly. The pluralism of styles, paradigms, and models are mediated by practice. Indeed, plurality of practices is a consequence of the fact that reality is complex and that many points of view are needed to understand it, and to intervene in it (e.g., Wimsatt, 2007; Winther, 2011a). Finally, styles are "ways of finding out about the world" (Hacking, 2009, p. 13); they are the most general category with which we shall be concerned, constraining and constituting paradigms and models.

\section{Styles}

In the 1980s and 1990s, A.C. Crombie and Ian Hacking developed the notion of styles of scientific thinking. ${ }^{3}$ A style is a systematic way of approaching the world scientifically. According to
Crombie, each of six styles "introduced new objects of scientific inquiry and explanation, new types of evidence, and new criteria determining what counted as the solution of a problem" (1994, vol. 1, p. 83). Crombie describes styles of scientific thinking thus:

The scientific movement brought together in its common restriction to answerable questions a variety of styles of scientific argument, of scientific methods of inquiry, demonstration and explanation, diversified by their subject-matters, by general conceptions of nature, by presuppositions about scientific validity and cogency, and by scientific experience of the interaction of programmes with realizations. (p. 83)

Each style collates general aspects of inquiry, methodology, and world-view.

Here are synopses of each style from Crombie $(1996)^{4}$, together with the name I shall use:

Axiomatic "Postulation was the primary and continuing style, invented by the Greeks in two different forms. The former exploited the demonstrative power of geometry and arithmetic in the simpler regularities of nature, uniting all the mechanics and music, under a common form of proof. The latter exploited the demonstrative power of logic as established by Aristotle in all the natural sciences as well as in other subject-matters of philosophy" (p. 74).

Experimental "The experimental argument, both to control postulation and to explore nature by designed observation and measurement, was developed as a strategy of searching for principles in more complex subject-matters, proceeding by an antecedent theoretical analysis" (p. 74).

Hypothetical-Analogical "Hypothetical modeling, proceeding likewise by an antecedent theoretical analysis, was developed as a method of elucidating the unknown properties of a natural phenomenon by simulating the phenomenon with the known properties of a theoretical or physical artifact" (p. 74).

Taxonomic "Taxonomy emerged as an explicit logic of classification, developed first by Plato and Aristotle. In many ways it is the foundation of all natural science, establishing fundamental similarities and differences" (p. 75).

Probabilistic "Probabilistic and statistical analysis arose, first in Greek medicine and Roman law, out of the need for a precise logic of decision in practical situations of contingent expectation and uncertain choice, and later the explicit discovery in the 17 th century of statistical regularities as a new form of regularity found in adequately numerous populations of events" ( $p$. 75).

Genealogical "Historical derivation, the analysis and synthesis of genetic development, was introduced by the Greeks in their search for the origins of human civilization and within it of language. Thus Diodorus Siculus and Lucretius envisaged a causal historical process of nature and mankind in which the past could be inferred from observation of present regularities, and the present could be explained as a development of that past brought about by natural laws" (p. 75).

These styles immediately exhibit some interesting features. All styles start in Ancient Greece. ${ }^{5}$ The experimental style "control[s]" the axiomatic style. Both experimental and hypothetical-analogical styles start with "theoretical analysis." The taxonomic style is a "foundation" to all of science, and thus the styles seem to be always-already hybridized. Moreover, the first three styles concern "the subject-matter of individual regularities," the second three

\footnotetext{
${ }^{3}$ Hacking has, at different times, preferred to call them styles of "reasoning" (2002a, 2002b, 2002c) or "thinking and doing" (2009). I believe that "research" and "inquiry" are also virtuous terms, as they emphasize that collective effort, problem-solving, and theory intertwined with practice are involved in each style.

4 These descriptions are similar to, but more crisp than those found in Crombie (1994); see also Crombie (1988).

5 In his 1994 work, Crombie had argued that the probablistic style "initiated in early modern Europe" (p. 85); Hacking (2009) suggests alternative origin stories. 
"the subject-matter of regularities of populations ordered in space and in time." (Crombie, 1994, p. 83). Finally, each style is distinguished by its "objects" and "modes of reasoning" (Crombie, 1994; Hacking, 2009).

Let us turn to Hacking's analysis of styles. I suggest that Hacking develops three characteristics of styles: they (1) construct possibilities of truth, (2) are self-authenticating, and (3) crystallize at certain historical moments, and are represented by trailblazers.

First, Hacking analyzes a particular function of styles: construct possibilities of truth. Hacking writes:

Every style of reasoning introduces a great many novelties including new types of: objects; evidence; sentences, new ways of being a candidate for truth or falsehood; laws, or at any rate modalities; possibilities. One will also notice, on occasion, new types of classification and new types of explanations. (2002c, p. 189)

To say that styles introduce "new ways of being a candidate for truth or falsehood" (Hacking, 2002c, p. 189) is to say that meaning and assertability criteria for some statements do not exist until a style of scientific research brings them forth. Prior to this, whole classes of statements simply lack positivity, a possibility of being true-or-false. For instance, in his The Emergence of Probability, Hacking (2006) defends the thesis that statements about the chance or frequency of events did not even make sense before the introduction ca. 1660 of the very concept of probability, of practices for calculating chances, and of social systems employing chances and frequencies. Indeed, in his classic "Language, Truth, and Reason," the text crystallizing styles of scientific reasoning themselves, and the text celebrated at the 2011 Cape Town conference, Hacking writes: "many categories of possibility, of what may be true or false, are contingent upon historical events, namely the development of certain styles of reasoning" (2002b, p. 175).

Put differently, in constructing possibilities of truth, styles provide conditions of objectivity in that they produce propositional objects that now have positivity (e.g., probability statements, or assertions about natural kinds or classes under the taxonomic style), and they provide methods of verification through which we go about establishing the truth-value of those very propositional objects. However, while a style is necessary for particular statements to have positivity, empirical investigation provides the actual truth-value. Truth-values of statements still depend on facts of the matter.

The second characteristic of Hacking's styles is that they are self-authenticating. Each style has a particular way of making its claims objective, and of stabilizing its different parts and properties, through its practices. ${ }^{6}$ By producing, maintaining, and enforcing the criteria necessary for any meaningful scientific investigation, styles entrench themselves. Scientific research must follow the very style or styles giving rise to it.

In more recent work, Hacking has adopted Bernard Williams' (2004) analysis of truth and truthfulness. Truthfulness is "telling the truth about something." Moreover, "the truthful person is both quite accurate and quite sincere" (Hacking, 2009, p. 33). Styles provide new ways of truth-telling. In order to define a style, Hacking introduces two "schemas" (2009, pp. 33-36):

(*) A shift in conceptions of what it is to tell the truth about X. $(* *)$ This significant change took place in the Y century, and its emblem is $Z$.
The following two examples help motivate intuitions about these criteria: (1) for the Greek axiomatic method of postulation, " $\mathrm{X}=$ geometrical relations, $\mathrm{Y}=$ early in the sixth century $\mathrm{BCE}$, and $Z=$ Thales" (Hacking, 2009, p. 36); (2) for the experimental method, $\mathrm{X}=$ "the minute unobservable parts of material naturewhat in quite recent times philosophers came to call theoretical entities", $Y=$ mid seventeenth century, $Z=$ Boyle and his air-pump. (p. 43) Hacking calls $\mathrm{Y}$ the moment of "crystallization" and $\mathrm{Z}$ a "trailblazer" (p. 36). Styles crystallize at particular historical moments, and are represented by trailblazers. Hacking's analysis here marks a difference with Crombie. Crombie's history is one of strong continuities; Hacking adds sharp breaks. ${ }^{7}$

In this section, I have presented some key features of Crombie's and Hacking's respective analyses of styles (see also Kwa, 2011). A broad range of research programs are possible in the context of a given style. This is especially true if we consider the fact that styles can hybridize and be multiply realized. Indeed, many paradigms and an even broader array of models can be guided by, and inherit properties from, a given style. Below in section (5), I return to Crombie's classification of styles, also endorsed by Hacking.

\section{Paradigms}

Kuhn's paradigms are the second category here analyzed. Kuhn (1970) introduced paradigms stating that they stemmed from the "classics of science," including “Aristotle's Physica, Ptolemy's Almagest, Newton's Principia and Opticks, Franklin's Electricity, Lavoisier's Chemistry, and Lyell's Geology" (p. 10). The term is polysemous. It can mean:

(1) A standard exemplar. This could be a new mathematical procedure (e.g., "Maxwell's mathematization of the electromagnetic field") or experimental set-up (e.g., "Lavoisier's application of the balance," p. 23)

(2) The general framework ("disciplinary matrix", 1969, postscript, p. 182) with various components:

a. laws and symbolic generalizations (e.g., $F=m a$ )

b. ontological assumptions

c. values (e.g., theoretical virtues such as simplicity, accuracy, and plausibility)

d. exemplars

(3) The sociological community embedding and co-constituting the paradigm. Kuhn distinguished theory and experiment from their community of origin. This third sense of paradigm appeals directly to the nature and practices of the social group in order to individuate a paradigm. ${ }^{8}$

The "puzzle-solving" of "normal science" occurs within a paradigm. Although most of science is normal, anomalies accumulate. When anomalies are numerous or significant, or both, a crisis ensues. Crises are typically resolved through a revolution, with the adoption of a new paradigm. (On rare occasions, a crisis can defuse with the old paradigm declaring victory, see Kuhn, 1970 , p. 84 ; time, of course, is every paradigm's enemy.) According to Kuhn, paradigms constitute and periodize the history of science. One suggestion, here followed, is to interpret the three different meanings as components of a paradigm. In other words, paradigms consist of (1) symbolic generalizations, (2) ontological assumptions, (3) values, (4) exemplars, (5) sociological communities, and, in addition, (6) specific theories and experiments, (7) acceptable research questions, and (8) (partly reified) objects and processes. ${ }^{9}$

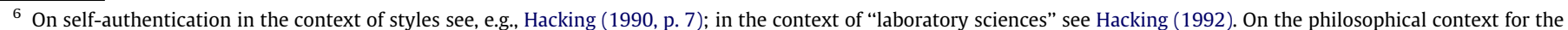
discussion of truth and styles, see Hacking (1975).

7 Jack Ritchie brought my attention to this key difference.

8 Masterman (1970) usefully spoke of "sociological paradigms."

9 I discuss the last three components of paradigms more fully in, e.g., Winther (in press).
} 
The above trichotomy finds support in the secondary literature. Godfrey-Smith (2003) differentiates between narrow and broad senses of the term. A paradigm, in the narrow sense, is "an achievement, or an exemplar" (p. 77). In the broad sense, "a paradigm is a package of ideas and methods, which, when combined, make up both a view of the world and a way of doing science" (p. 77). Hacking (1981) distinguishes between paradigm-as-achievement, i.e., "the accepted way of solving a problem which then serves as a model for future workers," and paradigm-as-set-of-shared values, i.e., "the methods, standards, and generalizations shared by those trained to carry on the work that models itself on the paradigmas-achievement" (p. 2-3). Hacking also considers the "social unit that transmits both kinds of paradigm" (pp. 3). Godfrey-Smith's and Hacking's distinctions echo Kuhn's own differentiation of "two main senses" of the term paradigm: "disciplinary matrix" and "exemplars" (Kuhn, 1977, pp., 462-463).

Paradigms provide a swath of concrete content to scientific research, including exemplars, symbolic generalizations, and ontological assumptions. Paradigms have significantly more specific content than styles, and are (roughly) nested within them. Discontinuous and punctuated change occurs both in the crystallization of styles, and in revolutionary episodes ushering in a new paradigm (Table 1 ).

\section{Models}

What is a model? In 1913, Bohr presented a model of the atom as a solar system, as well as a mathematical model intended to explain the spectral emission lines of atomic hydrogen. In 1899, Freud postulated an unconscious mind filled with particular desires, which could be satisfied in dreams or lead to neuroses, or both. In 1953, Watson and Crick presented a double-helix scale model of DNA. There is a plurality of models, and forms of modeling.

In the philosophy of science, the Semantic View of Theories of especially Patrick Suppes, Bas van Fraassen, and Frederick Suppe put models center-stage. Three points summarize the main teachings of the Semantic View:

(1) theory consists of mathematical models

(2) theory semantics (i.e., theory-world relations) rather than theory syntax, are of central philosophical interest

(3) experiment is subordinate to theory

Let us explore each in turn.

According to the Semantic View, theory is best characterized by mathematical models, rather than by axioms and theorems written in an uninterpreted and abstract formal language. For instance, van Fraassen argues:

to present a theory, we define the class of its models directly, without paying any attention to questions of axiomatizability, in any special language, however relevant or simple or logically interesting that might be. And if the theory as such, is to be identified with anything at all-if theories are to be reified-then a theory should be identified with its class of models. (1989, p. 222)

Thus, theory for van Fraassen consists of mathematical models. Indeed, on this view, and following Patrick Suppes, van Fraassen observes, "the correct tool for the philosophy of science is mathematics, not metamathematics [as it had been for the Syntactic View]" (van Fraassen 1989, p. 222).

The view is called "semantic" because the relation between mathematical structures and the empirical world are highlighted. Syntax qua mathematical structures presented either in state space (van Fraassen, 1970) or set theory (Suppes, 1960; Suppes, 1962) is not considered uninteresting, but semantics receive the bulk of philosophical attention. Reference, representation, and realism are central topics. For instance, empirical adequacy is critical to theory semantics: "The notions of empirical adequacy and empirical strength, added to those of truth and logical strength, constitute the basic concepts for the semantics of physical theories" (van Fraassen, 1980, p. 68). Van Fraassen (1989) and (2008) articulated empirical adequacy in terms of theoretical models embedding data models ${ }^{10}$. Embedding is a one-to-one mapping of a mathematical structure (or part thereof), to another mathematical structure (or part thereof); it is an isomorphism relation (see also Bueno, 1997; French \& Ladyman, 1999). Indeed, "phenomena are, from a theoretical point of view, small, arbitrary, and chaotic-even nasty, brutish, and short...-but can be understood as embeddable in beautifully simple but much larger mathematical models" (van Fraassen, 2008, p. 247; see also van Fraassen, 1989, p. 230). Data models directly represent the phenomena while theoretical models embed data models. That is one version of theory semantics.

The design, protocols, and results of experiments are integral to theory articulation and testing. Suppes (1960) identified theory confirmation as a central function of "the experimental experience" (p. 297). Frederick Suppe argues that "theories are experimentally related to phenomena in the experimental testing and confirmation of theories" (Suppe, 1989, p. 118). Finally, van Fraassen's succinct slogan encapsulates the Semantic View's perspective on experiment: "experimentation is the continuation of theory construction by other means." (stated identically, and with emphasis, in van Fraassen 1980, p. 77, 1989, p. 232, 2008, p. 112). Note that there is a subtle difference between Suppes' and Suppe's claims, and van Fraassen's play on von Clausewitz-experiment as theory testing, and experiment as engaging in (theoretical) activities in which the machinery of theory itself cannot partake (e.g., filling in the blanks of the physical constants of nature). While the Semantic View considers both roles important, in both cases experiment is subordinate to theory. The task of theory's handmaiden is to produce phenomena that can be suitably abstracted, idealized, and formalized in data models.

Pragmatics was largely absent from the Semantic View. ${ }^{11}$ That is, contextual factors such as practices and socio-historical background, as well as the nature of theory developers and users (i.e., the agents, together with the agents' intentions and ideals) were not investigated philosophically. Examinations of the plurality of models and modeling forms-e.g., diagrams, narratives, and model organisms-were also absent from the Semantic View.

Interestingly, such pragmatic factors had already been identified in the 1960s. For instance, the Belgian philosopher of science Leo Apostel wrote: "Let then $\mathrm{R}(\mathrm{S}, \mathrm{P}, \mathrm{M}, \mathrm{T})$ indicate the main variables of the modelling relationship. The subject $S$ takes, in view of the purpose P, the entity M as a model for the prototype T" (1960, p. 128). Moreover, the pioneer of artificial intelligence, Marvin Minsky argued:

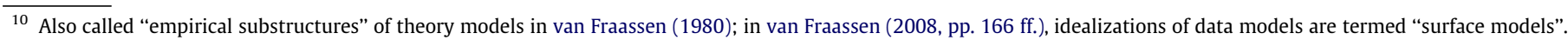

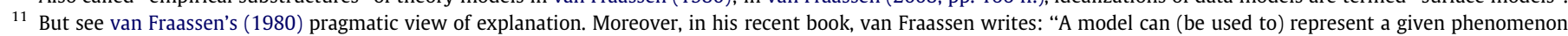

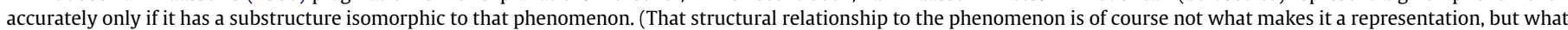

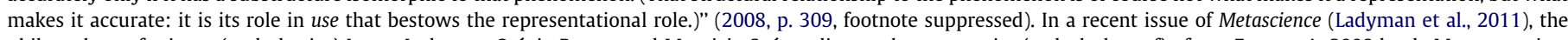

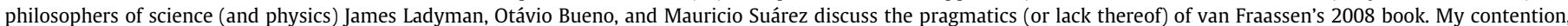

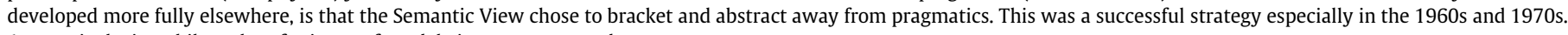
A more inclusive philosophy of science of models is now warranted.
} 
We use the term "model" in the following sense: To an observer $B$, an object $A *$ is a model of an object $A$ to the extent that $B$ can use $A *$ to answer questions that interest him about $A$. The model relation is inherently ternary. Any attempt to suppress the role of the intentions of the investigator B leads to circular definitions or to ambiguities about "essential features" and the like. (1965, p. 45)

This "pragmatic turn" reached core philosophy of science in the 1980s, especially through the work of Nancy Cartwright on models and modeling, and Ian Hacking on intervening through experiment. Here is Cartwright:

To explain a phenomenon is to find a model that fits it into the basic framework of the theory and that thus allows us to derive analogues for the messy and complicated phenomenological laws which are true of it. The models serve a variety of purposes, and individual models are to be judged according to how well they serve the purpose at hand. (1983, p. 152)

In addition to her contributions to the philosophy of explanation, causation, and laws of nature, her concern with the pragmatics of modeling has remained strong (e.g., Cartwright et al., 1995; Suárez \& Cartwright, 2008). The "models as mediators" school (Morgan \& Morrison, 1999) also focuses on the pragmatics and plurality of scientific models and modeling. ${ }^{12}$

I wish to stress the specificity of models as compared to the generality of styles and paradigms, as well as the importance of syntactics, semantics, and pragmatics to the content and plurality of models and modeling. ${ }^{13}$

\section{Dynamics of interweaving}

Now that we have reviewed each category in turn, let us focus on their interrelationships. Here I investigate the general dynamics of interweaving. This is the heuristic image calibrating the discussion: models are nested within (and guided by/realize) paradigms which, in turn, are nested within (and guided by/realize) styles. Three sorts of relations between higher-level and lower-level categories are considered: guidance, realization, and inheritance. Moreover, new parts and aspects sometimes emerge at lower-level categories. While this false and idealized image is a good start, various complications exist. After all, scientific practice involves hybridization within a level, as well as multiple realization across levels.

These are the three relations considered:

(1) Realization relation: In the philosophy of mind, the relation between mental states and brain states is typically understood as one of instantiation or implementation. According to Putnam's early functionalism, the relation between mind and brain is the same as the relation between abstractly described Turing machines and organized matter (e.g., Wilson \& Craver, 2006). Under my analysis of interweaving categories, there is, in part at least, an abstract-concrete relation between styles and paradigms, paradigms and models, and styles and models. The latter member of each pair instantiate and implement the former member. What it is to be a style is the paradigms, and particularly the models, that realize that style. Moreover, the realizing paradigms or models are more concrete, and closer to the actual richness of practice, theory, and agents of science than the style. The three categories are nested in an abstraction hierarchy.

(2) Guidance relation: In another sense, however, the three categories exist on the same level of abstraction. Or rather, they have a set of guidance relations in which higher-level categories constrain the properties and parts of lower-level categories. This guidance is mediated by practices. That is, the family of practices belonging to a style guides the more specialized and nuanced family of practices within a paradigm. The style is the whole, the paradigm the part. The guidance mediated by this part-whole relation is strong in that it constrains the lower-level practices, but it is also weak in that it frames and accommodates new and more niched families of practices at the lower levels.

(3) Inheritance relation: Both the abstract-concrete realization relation and the practice-mediated part-whole guidance relation involve, in different ways, the inheritance of properties and components of scientific practice and theory from higher levels to lower levels. Inheritance is here used in the object-oriented programming sense in which whatever behaviors and attributes one assigns to objects of a particular class can be inherited by-absorbed by, given to-objects of another class, at lower levels of categorization.

To get a better sense of our hierarchical image, consider Hacking's comparison of styles and paradigms:

A style of reasoning is very different [from a paradigm]. It tends to be slower in evolution, and vastly more widespread. Within that style of reasoning I call statistical inference, there are many different paradigms associated with names such as Neyman, Fisher, or Bayes. A style of reasoning need not be committed to any positive items of knowledge. A paradigm surely assumes certain propositions as taken for granted: they are part of the achievement that sets the model for future work. They are stated in the paradigmatic textbooks. A style of reasoning makes it possible to reason towards certain kinds of propositions, but does not of itself determine their truth value. Even the Euclidean geometrical style does not fix which propositions are going to come out as theorems. (1985, p. 149)

A style contains and guides many paradigms. For instance, the probabilistic style guided Neyman's emphasis on hypothesis testing in scientific inference, Fisher's frequentism and maximum likelihood methodology, and Bayes' presentation of probability in terms of prior and updated distributions. Indeed, Neyman, Fisher, and Bayes-and their respective followers, under each of the three paradigms-are all constrained by, and work under, the long-term probabilistic style. General styles do not contain as much specific content (properties and parts) as the paradigms realizing them. Moreover, the practices of the style are inherited by paradigms, and then by models, with increasing specificity and specialization at each level.

The actual workings of science include multiple realization among category levels and hybridization within a level. First, there is multiple realizability in that the same style can be realized in, guide, and inherit practices to multiple paradigms. ${ }^{14}$ Second, different styles can be hybridized into a single style, under some classifications (e.g., the Galilean Style, which I call mathematical modeling

\footnotetext{
12 In Winther, 2012, I develop an explicit pragmatics of modeling.

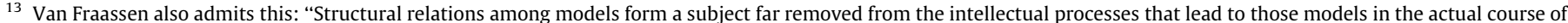

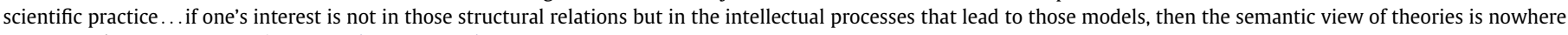
near enough to pursue one's interests" (2008, p. 311).

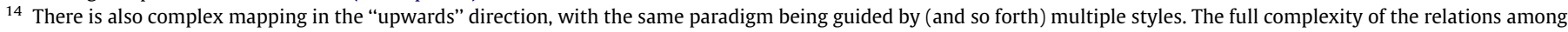
the three categories here explored requires further study.
} 
Table 1

A summary of the basics of each category discussed in this paper.

\begin{tabular}{|c|c|c|c|}
\hline & Styles & Paradigms & Models \\
\hline $\begin{array}{l}\text { Components and } \\
\text { Characteristics }\end{array}$ & $\begin{array}{l}\text { - objects and methods } \\
\text { - introduction of laws and sentences } \\
\text { - construction of possibilities of truth } \\
\text { - crystallization } \\
\text { - self-authentication } \\
\text { - plurality } \\
\text { - agents and history } \\
\text { - general practice }\end{array}$ & $\begin{array}{l}\text { - symbolic generalizations, ontological } \\
\text { - sssumptions, values, exemplars } \\
\text { - theories and experiments } \\
\text { - research questions } \\
\text { - objects and processes } \\
\text { - plurality } \\
\text { - agents and history } \\
\text { - specific practice } \\
\text { - representation }\end{array}$ & $\begin{array}{l}\text { - modeling methodology } \\
\text { - model structure and language } \\
\text { - data models embedded in theo- } \\
\text { retical models }\end{array}$ \\
\hline $\begin{array}{l}\text { 1. Creators/ } \\
\text { Defenders }\end{array}$ & 1. Crombie, Hacking & 1. Kuhn & 1. Suppes, Van Fraassen, Cartwright \\
\hline 2. Opponents & $\begin{array}{l}\text { 2. Methodological Universalists (e.g., Popper), Historical } \\
\text { Relativists (e.g., Late Feyerabend, Martin Kusch) }\end{array}$ & $\begin{array}{l}\text { 2. Syntactic View, Methodological } \\
\text { Universalists, Historical Relativists }\end{array}$ & 2. Syntactic View \\
\hline $\begin{array}{l}\text { 1. Standard } \\
\text { Examples }\end{array}$ & $\begin{array}{l}\text { 1. Axiomatic, Experimental, Probabilistic, Hypothetical- } \\
\text { Analogical, Taxonomic, Genealogical }\end{array}$ & 1. Copernican, Newtonian, Darwinian & $\begin{array}{l}\text { 1. London Equations, DNA scale } \\
\text { model, Hardy-Weinberg theorem }\end{array}$ \\
\hline $\begin{array}{l}\text { 2. Examples from } \\
\text { Systematics }\end{array}$ & 2. Taxonomy, History, Mechanism, Mathematical Modeling & $\begin{array}{l}\text { 2. Linnaean, Phylogenetic-Darwinian, } \\
\text { Probabilistic-Cavalli-Sforza-Edwardian }\end{array}$ & $\begin{array}{l}\text { 2. Great Chain of Being, Tree of Life, } \\
\text { Network of Life }\end{array}$ \\
\hline
\end{tabular}

below). The best way to instantiate our perhaps too general discussion is to turn to a brief history of systematics (section 6).

Table 1 summarizes some of the main points regarding interweaving categories-i.e., our exploration of simultaneous relations among styles, paradigms, and models.

\section{A brief history of systematics}

Here I sketch a history of systematics, in terms of the following interweaving categories:

i. Styles
a. Taxonomy
b. History
c. Mechanism
d. Mathematical Modeling

ii. Paradigms
a. Linnaean
b. Phylogenetic-Darwinian
c. Probabilistic-Cavalli-Sforza-Edwardian

iii. Models
a. Great Chain of Being
b. Tree of Life
c. Network of Life

I explore each in turn.

\subsection{Styles}

The account of styles here presented builds on Crombie's and Hacking's classification, but rearranges and reanalyzes it in light of the biological sciences, particularly systematics. (My classification is also pertinent to related sciences, such as the biomedical and cognitive sciences). Taxonomy and history remain unchanged. However, I focus on the mechanistic part of the hypotheticalanalogical style, a style which did not significantly include mathematical models. Moreover, axiomatic and probabilistic styles are, I suggest, parts of a mathematical modeling style. Experiment is here interpreted as a further part of mathematical modeling. It should also be analyzed as standing alone; such an analysis of experiment as an independent style in other biological sciences besides systematics is critical for future projects.

\subsubsection{Taxonomy}

The taxonomy style first appeared in "ancient Egyptian and Babylonian medical practice" and its rules were made explicit in Greek medicine: "collections of usually or always associated diagnostic signs or symptoms or conditions for diseases or for cures by drugs. . . were identified by a name, placed in a classification, and finally attributed with a common nature or specific cause." (Crombie, 1994, v. 2, p. 1245) It was Aristotle, particularly in the introduction to On the Parts of Animals (PA), who first explored principles of classification. The "method of dichotomy" or "division", favored by Plato and the Academy and which Aristotle had favored earlier in his development (see Lloyd, 1961), was now deemed either impossible or futile (PA 644b20). Aristotle realized that species, which he considered real, differed from one another in a great variety of differentiae. Cross-cutting classifications are thus possible. First, this is because no division is perfect. There are almost always intermediate cases: "Seals are between land-animals and water-animals, bats between land-animals and fliers: thus they belong to both classes or to neither." (PA 697b2) As Lovejoy writes: "she [i.e., 'nature'] loves twilight zones" (1936, p. 56). Such intermediary types force the choice of some differentiae over others, if two classes (Fishes and Mammals) rather than three (Fishes, Mammals, and Seals) are desired. Second, for any set of differentiae chosen, there is always at least one other set of differentiae that will give another classification (even ignoring intermediary types, see Sloan, 1972). What is Aristotle's solution to twilight zones and to the forced choice among various differentiae?

Aristotle's taxonomic logic combined conventional knowledge with essentialist thinking. While he appealed to making divisions according to the "essence of a thing" (alternative translation: "a thing's substantial being") (PA 643a27-28), he also believed that in identifying the groups (classes) to be organized, we should "follow[] the lead of the bulk of mankind" (PA 643b11, 644b). Thus, he implicitly argues that reasonable folk classifications had latched on to the Essence of Species. He is typically seen as "the great representative of a logic which rests upon the assumption of the possibility of clear divisions and rigorous classification" (Lovejoy, 1936, p. 57), but it is important to remember that he also "first suggested the limitations and dangers of classification" (Lovejoy, 1936, p. 58). As all great thinkers, Aristotle is complex, even paradoxical.

Without providing either a foolproof logic of classification or even a single, consistently followed systematic classification, ${ }^{15}$

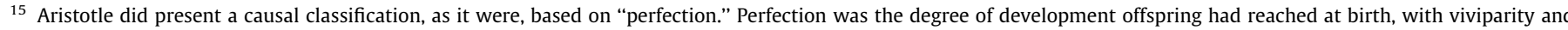
particularly man, being the most perfect, followed by a half-dozen or so increasingly imperfect groups, see Generation of Animals, $732 \mathrm{~b}$ ff.
} 
Aristotle crystallized a whole new way of thinking, doing, and inquiring-the taxonomy style. In doing so, Aristotle made explicit new sorts of sentences (e.g., "Man is a biped"), objects (e.g., "species", "differentiae") and methods (e.g., characterize the explanatory four causes of particular species, arrange species under groups). Moreover, Aristotle created what I consider to be taxonomy's three tasks (see Peter Stevens' distinction between "grouping" and "ranking", 1994, p. 10, and GCD Griffiths' distinction between "classification" (isomorphic to ranking) and "systematization", ${ }^{16}$ 1974):

(1) Identify relevant and "natural" groups, at any organizational level (Stevens' grouping)

(2) Classify these groups logically with respect to one another, employing characters (or more recently, distance measures) (Griffiths' classification/Stevens' ranking)

(3) Provide a causal explanation, of whatever sort (e.g., developmental, phylogenetic) to interpret or explain the classification (Griffiths' systematization).

Aristotle's great influence lies in making these aims of taxonomy both possible and actual.

\subsubsection{History}

History is one of the styles identified by both Crombie and Hacking: "[s]cientific historical derivation... may be dated from the Greek philosophical commitment in the 6th and 5th centuries B.C. to a world generated by a natural causal process embodying the operation of natural laws over a long time" (Crombie, 1994, v. 3, p. 1551). There is not a clear crystallizer for this style. In a philosophical, scholarly context, Hegel might be a good candidate: "It was to be Hegel who reduced the historical embodiments of ideas to a chronological and geographical sequence, and thereby projected into German and then more general Western scholarship further distinctive philosophies of history and programmes of research" (p. 1626). In systematics and the biological sciences more generally, the crystallizer is almost certainly Darwin. ${ }^{17}$ One passage from On the Origin of Species suffices to show the importance of history for Darwin: "I believe this element of descent is the hidden bond of connexion which naturalists have sought under the term of the Natural System" (1859/1964, p. 433). (For crystallizers of the history style in geology, consulting Gould, 1987, suggests James Hutton or Charles Lyell as plausible candidates.) Some recent commentators even go so far as defining biology as "accumulated history" (Stanley Salthe ${ }^{18}$, personal communication August 31, 2008) or "biology is about lineages" (David Wake ${ }^{19}$, personal communication July 18 , 2010). While history need not be imperialistic, such statements indicate the centrality of history and the history style to the biological sciences and, in conjunction with Darwin's statement, to systematics.

\subsubsection{Mechanism}

The mechanism style is close to the hypothetical-analogical style, which often relied on material or scale models, and attempted to explain the workings of nature through "the known properties of an artifact [e.g., an 'analogical model']" (Crombie, 1994, v. 2, p. 1087). In addition to the basics of Crombie's third style, the mechanism style is specifically concerned with elucidating the nature, structure, and process of causal mechanisms. In characterizing a mechanism, a functional system (or a physical model of it) is broken down in order to understand how it works. Of which (types of) parts does the system consist? How do these parts behave? What are the basic theoretical principles governing the parts as well as the system as a whole? Physiology, development, and even inheritance have been analyzed by the mechanism style. Descartes is arguably the crystallizer of this style. Crombie writes:

The animal automaton with which Descartes modelled natural physiology in L'Homme... we could suppose God to have constructed in his [i.e., Descartes'] imaginary new ['scientific fiction'] world with a system of tubes and openings capable of giving it a variety of movements by which it could imitate all those of our own functions which depended only on the material arrangement of organs. (1994, v. 2, pp. 1170-1171)

Descartes' analysis of animals as automata (even Homo sapiens qua physical, res materia) had a deep influence. Two other key figures and concepts that further articulated the mechanism style are Claude Bernard (1865/1957) and his "experimental medicine", and Wilhelm Roux (1905) and his "developmental mechanics". Some of the philosophical foundations of this style, in historical context, have been recently explored. For instance, Craver and Darden (2005) describe some "prominent ideas associated with the term 'mechanism"' (p. 234). In their discussion of mechanisms as machines, atomistic, and principle-governed, they discuss the importance of Galileo and Descartes, among other thinkers. ${ }^{20}$ In recent work (Winther, in press), I argue that the mechanism style searches for and constitutes mechanisms in four overarching strategies: (1) analysis, (2) physicochemical (PC) reduction, (3) causal surgery, and (4) mechanism transplantation.

In the context of systematics, mechanism focuses on inheritance and developmental processes, and even on behaviors and environmental processes underlying assortative mating and speciation. In other words, the processes underlying the continuity, separation, and local adaptation of lineages are the mechanisms pertinent to systematics. One of Willi Hennig's (1950/1965) contributions was to emphasize that while various systems are legitimately used to classify organisms (e.g., ecological, morphological, physiological), it is the phylogenetic system which should be made "the general reference system for... systematics" (1950/1966, p. 22). Moreover, for Hennig, phylogeny was closely tied to developmental, geographic, and environmental mechanisms:

The definition of the concept 'phylogenetic relationship' is based on the fact that reproduction is bisexual in the majority of organisms, and that it usually takes place only within the framework of confined reproductive communities which are genetically isolated from each other. (Hennig, 1965, p. 97)

Mechanisms are essential to research in systematics. Indeed, the mechanism style is necessary for achieving (in the context of systematics) the third aim of the taxonomy style: to provide a causal explanation for interpreting and/or explaining a given classification.

\subsubsection{Mathematical modeling}

This is not a style identified by Crombie and Hacking, yet it combines three of their styles, not yet here discussed: axiomatic,

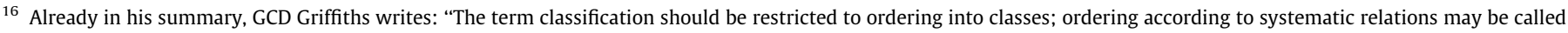

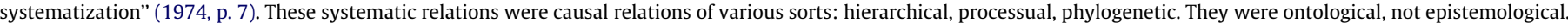

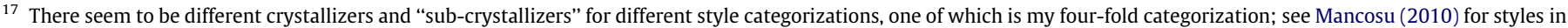

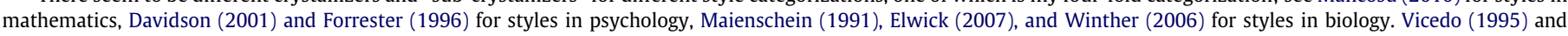
Pickstone (2000) comment on key, general aspects of styles.

18 CUNY emeritus; Univesity of Copenhagen affiliated researcher.

19 University of California, Berkeley.

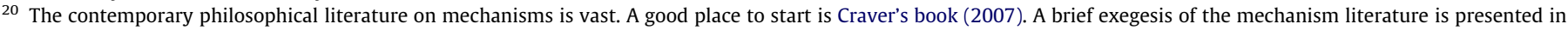
Winther (2011a)
} 
experimental, and probabilistic. Because of his analyses on idealization and mathematical abstraction, as well as on the relation between mathematical theory and experiment, I take Galileo Galilei to be the crystallizer of mathematical modeling (e.g., McMullin, 1985). The probabilistic style was added to mathematical modeling in the 19th century, especially through statistical mechanics, which was a partial precursor of the population genetics work of R. A. Fisher. Simulations followed the advent of computers and computer science in the 20th century (e.g., Winsberg, 2010), and are perhaps a whole new style (Hacking, personal communication, March $20,2007)$; they are also part of the broad style of mathematical modeling.

A little more detail on Crombie's and Hacking's take on Galileo would be useful for the purpose of characterizing mathematical modeling. Hacking holds that the Galilean style "remain[s] at the level of... hypothetical modeling." (2002c, p. 184) He recently reasserted this judgment: "The Galilean style is the crystallization of what Crombie called the style of hypothetical modelling, and of course its iconic trailblazer is Galileo" (2009, p. 42). Yet, in his earlier "Language, Truth, and Reason" (2002b), Hacking did not identify the Galilean style with any particular style that Crombie had first suggested at a 1978 conference in Pisa (Crombie, 1981) ${ }^{21}$. Hacking had simply referred to Weinberg's (1976) and Chomsky's (1980) discussions of the Galilean Style, following Husserl,22 as a kind of justification for using the very word style (2002b, pp. 161-162). There are thus two Hackings on Galileo. Early Hacking is more accurate here. Because (1) Crombie (1981) does not place Galileo under any style, (2) Galileo is primarily discussed in the experimental style section ${ }^{23}$ of Crombie (1994), and (3) the hypothetical-analogical ${ }^{24}$ style of Crombie (1994) barely includes mathematical models, Late Hacking's 1992 and 2009 mapping of the Galilean style to Crombie's third style seems ungrounded. Indeed, Galileo was a multifaceted thinker and doer:

Whether we see Galileo as a Platonist for whom the book of nature was written in mathematical language, or as a Renaissance artist-engineer who sought to control his materials by taking nature to pieces in a workshop in order to reassemble it from then known principles, he acted also as a humanist scholar debating the best ancient models for true scientific thinking. (Crombie, 1981, p. 278)

Galileo Galilei was a mathematician, an artist-engineer-experimenter, and even a humanist. I take especially the first two to be essential aspects of the broad style of mathematical modeling.

In systematics, the mathematical modeling style was largely absent until the mid 20th century. This was because significant computational power, as well as theory and practice from probability theory and statistics, were required in order to usefully organize large amounts of taxonomic data. Sokal and Michener (1958), and the phenetic program they spawned, were the revolutionaries of mathematical modeling in systematics. However, as we shall see, it was the collaborative mathematical work of Cavalli-Sforza and Edwards that had the most significant long-term influence.

\subsection{Paradigms}

In what follows, I identify three paradigms critical to the history of systematics. Note that each involved a revolutionary (or revolutionaries) who wrote a critical text(s), roughly in the middle of each of the last three centuries: (1) Linnaeus and his Systema Naturæ (first edition 1735; influential tenth edition 1758 , volume 1 , and 1759 , volume 2), (2) Darwin and his On the Origin of Species (influential first edition 1859; five subsequent editions), and (3) Cavalli-Sforza and Edwards and their collaborative papers in the 1960s.

\subsubsection{Linnaean}

Linnaeus was obviously the father of the Linnaean paradigm. As is well known, his system of classification involved binomial nomenclature, a logical hierarchy of five ranks (kingdom, order, class, genus, and species), and a focus on a critical sub-set of characters, especially the reproductive characters of plants. While he did worry about hybridization, his world-view was hardly evolutionary. He was concerned with presenting the natural system as organized by the single deity. Here is not the place to discuss, as it were, orthodox (e.g., Ereshefsky, 2001) and revisionist (MüllerWille, 2007) interpretations of Linnaeus. Whatever the complexities of his theory and practice, Linnaeus introduced and reified a paradigm that valued a single natural classification of organisms into tight and separable logically hierarchical groups (according to just a few characters, rather than according to all characters with cross-cutting and even conflicting multiple classifications resulting, as Michel Adanson had taught). As an exemplar of this paradigm stands Linnaeus' 1735 (Systema Naturæ) classification of Homo sapiens within the natural system, including a sub-division into four varieties: europæus, americanus, asiaticus, africanus.

\subsubsection{Phylogenetic-Darwinian}

The phylogenetic-Darwinian paradigm holds that taxonomies must reflect the evolutionary process as captured in phylogenetic trees, called cladograms. Parsimony is also seen as the best method for inferring such trees. In order for our classifications to be natural and objective, they must refer to systematizations captured in cladograms. Cladograms show a nested clade structure. As Darwin (1859) wrote "all true classification is genealogical" (p. 420). According to the work of Hull (1988), Mishler (2000, 2009), and Sober (1988, 2004) the revolution commenced in Darwin's work, but was consummated in Willi Hennig's work. It continues to be strong in the range of methods available today for character analysis, phylogenetic inference, and naming. There are ontological assumptions of various sorts, values (e.g., maximum parsimony as the best criteria for building trees), and exemplars (e.g., the simple methodology of classifying according to shared derived characters) built into this paradigm. ${ }^{25}$ This paradigm was rather weak on mathematical modeling.

\subsubsection{Probabilistic-Cavalli-Sforza-Edwardian}

As is the case in many other areas of the biological sciences, the 1960s was a decade of algorithmic formalization. Tractable and

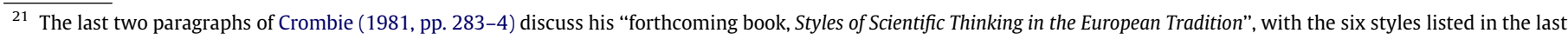

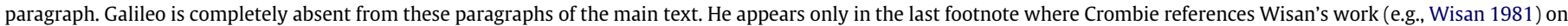
"Galileo's scientific style." In these last four lines of the entire article, Galileo is not tied to any of Crombie's styles. Moreover, Galileo is only mentioned, not used.

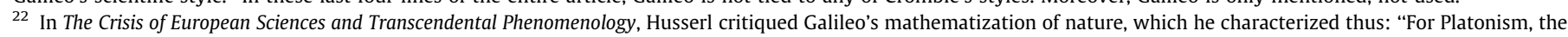

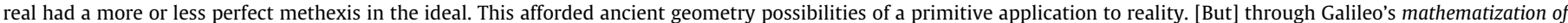

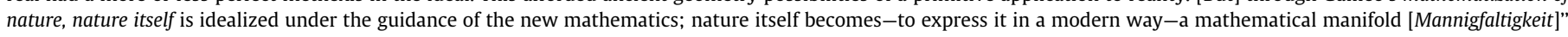
(Husserl, 1954/1970, p. 23, footnote suppressed). While they refer to Husserl, Weinberg and Chomsky praise rather than critique Galileo's mathematization of nature.

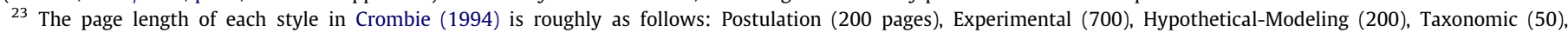

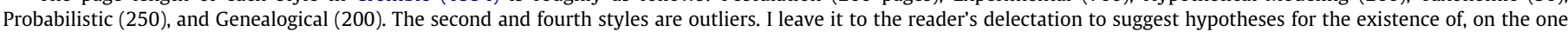
hand, extreme difference between the two outliers, and, on the other hand, relative equality among the remaining four styles.

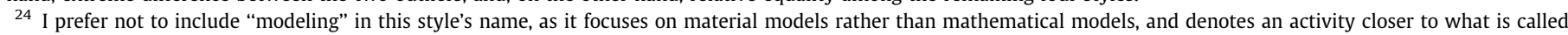

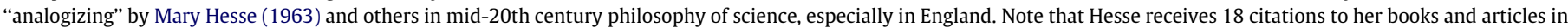
Crombie's bibliography; Hacking 19 citations, Kuhn 10, van Fraassen 3, and Suppes 3.

${ }^{25}$ In Winther (in press), the Phylogenetic-Darwinian paradigm is identified as the Cladism paradigm.
} 
useful mathematical models were finally developed, and calculations, analysis, and simulations could now begin to be carried out with the increasing computational power available. Probably the first work to develop algorithms relevant to systematics was Robert Sokal and Charles Michener's co-authored papers from 1957 and 1958. This is a reasonable candidate for revolutionary text. However, the phylogeneticist Joseph Felsenstein attributes correctly (in my estimation) the relevant paradigm shift for algorithmic methodologies to build and select the best trees to the work of Cavalli-Sforza and Edwards (e.g., Cavalli-Sforza \& Edwards, 1967; Edwards \& Cavalli-Sforza, 1964). According to Felsenstein "One of the foundations of numerical work on phylogenies was the remarkably creative work of Anthony Edwards and Luca CavalliSforza... Both had been students of the famous statistician and population geneticist R. A. Fisher. They were trying to make trees of human populations from gene frequencies of blood group alleles" (2004, p. 125). To just provide a flavor of the impact, Felsenstein in his 2004 chapter "A digression on history and philosophy" continues: "Edwards and Cavalli-Sforza's paper of 1964 is remarkable in that it introduces the parsimony method, the likelihood method, and the statistical inference approach to inferring phylogenies, all in one paper. It could have introduced the distance matrix method as well, but did not" (p. 128). This paradigm shift in methods of systematics was simultaneous with Hennig's cladistics, the explicit, consummated expression of the Phylogenetic-Darwinian paradigm.

\subsection{Models}

The recent literature on models and modeling methodologies is vast. Several anthologies describe a plurality of modeling methodologies, in addition to mathematical modeling. For instance, Laubichler and Müller, eds. (2007) focus on the biological sciences; Creager, et al., eds. (2007) explore "model systems" and "exemplary narratives" across the sciences, natural and human alike. The topic has also attracted significant attention in analytic philosophy of science. Standard examples of mathematical models in this literature are the London Equations of superconductivity (e.g., Cartwright et al., 1995; French \& Ladyman, 1997; Suárez \& Cartwright, 2008) and the Lotka-Volterra equations of predator-prey dynamics (e.g., Frigg, 2010; Weisberg, 2007). While this literature explicitly acknowledges that at least material and scale models (e.g., DNA scale model, airplane scale models used for wind tunnel testing) are bona fide models (e.g., Downes, 1992; Frigg, 2010), it is more skeptical about diagrams or narratives as models. Here I cannot do due justice to this variety of lucid case studies and impressive "philosophies of modeling".

My aim is to briefly motivate three models, and modeling methodologies, of the natural system, from antiquity until the present day. These models are not all mathematical. For instance, the Great Chain of Being is a metaphor and analogy, even a diagrammatic model, and was never a mathematical model. Moreover, the Tree of Life started out as a metaphor and analogy (a role it maintains) in the work of Darwin, and was rigidly analyzed as a diagrammatic and conceptual model in Hennig's work. Only within the Probabilistic-Cavalli-Sforza-Edwardian paradigm was a family of algorithmic methodologies developed to build and select the best trees, given a group of organisms and data. However, the Network of Life, as developed in the late $20^{\text {th }}$ century, was born as both a formalized mathematical model and as a metaphor and analogy.

\subsubsection{Great chain of being}

Perhaps the best summary statement of the Great Chain of Being model of life, a model central to the history of systematics, is Lovejoy's classic description: "composed of an immense, or ... of an infinite, number of links ranging in hierarchical order from the meagerest kind of existents, which barely escape non-existence, through 'every possible' grade up to the ens perfectissimum" (1936, p. 59). In many respects, the Linnaean paradigm employed this analogy and diagrammatic model in its presentation of the Linnaean hierarchy. This model has since been discarded, although it emerges repeatedly in a metaphorical and hidden manner in our ways of speaking about progress and level of complexity in the natural world (e.g., Gould, 1996; McShea, 1991).

\subsubsection{Tree of life}

Today, trees are often inferred through various mathematical modeling processes, as captured in the bottom three models and modeling methodologies of Fig. 1. Before the introduction of these methods with particularly Cavalli-Sforza and Edwards' work, trees were more "subjective", despite the best efforts of Julian Huxley, Ernst Mayr, and GG Simpson. Hennig was one of the workers who analyzed phylogenetic trees diagrammatically and conceptually, and thought carefully about the relation between causal phylogenetic trees and logical hierarchical classifications (e.g., Hull, 1988; Rieppel, 1988; Rieppel, 2010). This relation had already been delineated by Aristotle in the Taxonomy style, as we saw above. Darwin, of course, first presented the tree model explicitly, as the only diagram of his 1859 Origin.

\subsubsection{Network of life}

Ford Doolittle and his collaborators are perhaps currently the loudest opponents of the Tree of Life model, which they wish to "uproot" (e.g., Doolittle, 1999). The literature on Network of Life models and modeling methodologies is growing in influence and quantity. For metaphorical and conceptual aspects of Network of Life models, see, e.g., Woese (2000), Doolittle and Bapteste (2007). Recent mathematical modeling methodologies of the Network of Life are summarized in Huson, Rupp, and Scornavacca (2010). Of course, there are also strong critics (e.g., Mishler, 2000, 2009). It would be most interesting to consider hybrid treenetwork models, metaphorical, diagrammatic and mathematical.

\subsection{Getting the picture}

Here are some basic observations concerning Fig. 1. Interweaving styles, paradigms, and models provides tremendous insight into the history of systematics. We see that broad, general styles, with clear origins and trailblazers across the history of Western science and

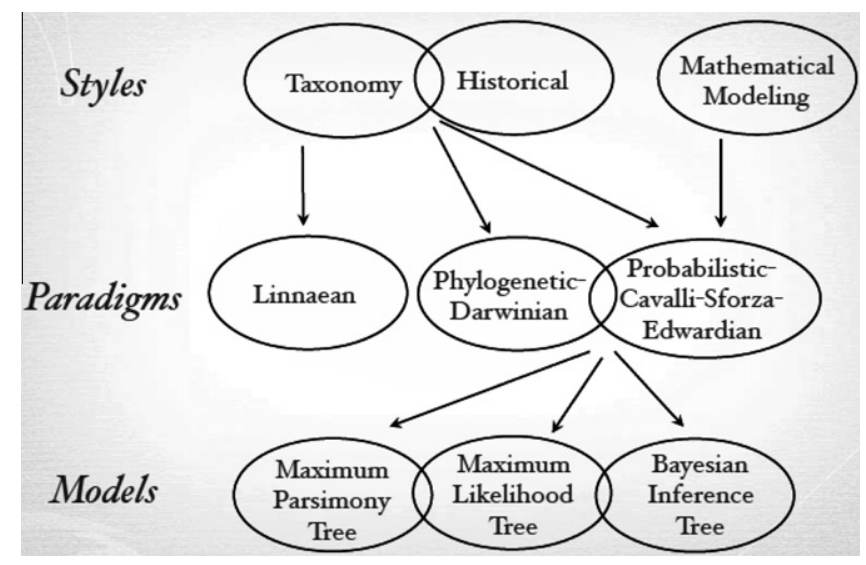

Fig. 1. Interweaving categories for a brief history of systematics. The arrows represent relations of realization, guidance, and inheritance. The diagram could also be redrawn as nesting the ellipses (potentially overlapping) at a given level (e.g., the three tree models) within the ellipses at the level immediately above (e.g., the overlapping paradigms of Phylogenetic-Darwinian and Probabilistic-Cavalli-SforzaEdwardian), thereby producing a set of ellipses within ellipses. However, relations would still have to be drawn with arrows, overlapping requires further conceptual articulation, and the diagram would be difficult to read. 
philosophy (Taxonomy: Aristotle, History: Hegel, Darwin, Mechanism: Descartes, Mathematical Modeling: Galileo), have been realized by, guided, and transmitted parts and properties to, the many paradigms and models of systematics. These paradigms and models have a history, social context, and agents. The picture I present in Fig. 1 is partial. I have not included the Great Chain of Being nor Network of Life models of systematics. But the picture shows the wealth of possible relations and insights of interweaving categories discussed in section (5) above, "Dynamics of Interweaving". For instance, we see hybridization between Phylogenetic-Darwinian and Probabilistic-Cavalli-Sforza-Edwardian paradigms, or even among the three critical families of mathematical models presented (the nature of the overlap between these models is a matter of debate, as Elliot Sober has analyzed extensively). When the hybrid paradigm depicted is realized in/is inherited in the three distinct mathematical modeling methods, multiple realizability is found.

Much more could be said, but I hope that the philosophical framework of interweaving categories in section (5), and the case study in this section, provide inspiration and food for thought about the general project of this article: to learn about the process and products, the practices and representations, and the socialtechnological impact of science by examining the general relationships among styles, paradigms, and models, and applying this analysis to at least one case study.

\section{Conclusion}

In this article, I have presented a basic analysis of each of the three chosen categories, styles, paradigms, and models. A false heuristic image-a hierarchy of nested levels-has been suggested as an idealized way of understanding the complex relationship among the three categories. This picture is a useful start, but nowhere near a complete analysis, as can be seen already when considering multiple realizability and hybridization. My philosophical investigation of interweaving categories is exemplified in a brief history of systematics. One can imagine other historical episodes from other sciences where the interweaving of categories would be useful (e.g., 20th century quantum mechanics and relativity theory, 19th century analytical/synthetic chemistry).

The general lesson of this article is that interweaving categories is instructive and empirically adequate to science. It helps bring new phenomena and new questions to light. Each category, as well as their interweaving, can be described in the way that Roger Ariew discussed styles, in his Isis review of Crombie (1994):

Since the six styles are neither mutually exclusive, nor totally exhaustive, nor categories that themselves would have historical legitimacy, one has to ask, What is the benefit of such historiography? The answer, of course, resides in the fruitfulness of the historical investigation that the structures command. And that is where the richness of Crombie's work lies. (Ariew, 1995, p. 82)

How can we provide a more complete and insightful rendition of the complexity of frameworks and categories operative in science? How are the analytical categories of those of us interested in conceptually analyzing science related? I emphasize a plurality of categories in science: many categories, at multiple levels of abstraction and parthood, simultaneously operative. We should do justice to this in our analyses of the history, philosophy, and sociology of science. I welcome other analyses that may choose other categories to interweave, or may choose to relate them in other ways, rather than in an abstract-concrete and part-whole hierarchical nesting. The point is that categories should be combined, both in general and for the case studies we choose to study.
Note that this article is a meta-meta analysis, from a scientist's point of view. An application of a single category (e.g., paradigm) to a historical episode (e.g., the Darwinian revolution) is a metaanalysis of the history. A philosophical evaluation of that category alone can be interpreted as either a meta or a meta-meta analysisI will not adjudicate that here. But a philosophical evaluation of categories, and examination of the way they fit together (or do not fit together) is clearly a meta-meta- analysis, in that analytical categories (and even meta-categories, e.g., a nested hierarchy, Fig. 1) are investigated comparatively, from a higher-level perspective. Moreover, the philosophical consequences of my meta-meta analysis for (1) the realism debates (wars?), (2) the project of Philosophical Anthropology (e.g., Hacking, Scott Atran), and (3) the relation between theory and practice ${ }^{26}$, also falls under the domain of my analysis, but will have to await future exploration.

\section{Acknowledgments}

Ian Hacking, Paolo Mancosu, Sergio Martínez, Lucas McGranahan, Olivier Rieppel, and Jack Ritchie kindly provided feedback on earlier versions of this article. Recent discussions on these topics with Claus Emmeche, Hervé Kieffel, Robert Kohler, Chunglin Kwa, Sabina Leonelli, John MacFarlane, Fabrizzio McManus, Amir Najmi, Mette Smølz Skau, and Michael Weisberg are much appreciated. Finally, I am grateful to audience questions and comments at the Philosophy Departments of the University of Cape Town, University of California, Berkeley, and San José State University, where this paper was presented.

\section{References}

Ariew, R. (1995). Feature review of AC Crombie (1994). Isis, 86, 82-161.

Bernard, C. (1957). An Introduction to the Study of Experimental Medicine. [Translation by Henry Copley Greene of Introduction à l'étude de la médecine expérimentale, Paris: J.-B. Baillière, 1865]. New York: Dover.

Bueno, O. (1997). Empirical adequacy: A partial structures approach. Studies in History and Philosophy of Science, Part A, 28, 585-610.

Cartwright, N. (1983). How the laws of physics lie. New York: Oxford University Press.

Cartwright, N., Shomar, T., \& Suárez, M. (1995). The tool box of science: Tools for the building of models with a superconductivity example. In W. Herfel, W. Krajewski, I. Niiniluoto, \& R. Wojcicki (Eds.), Poznan studies in the philosophy of the sciences and the humanities. Theories and models in scientific processes (Vol. 44, pp. 137-149). Amsterdam: Rodopi.

Cavalli-Sforza, L. L., \& Edwards, A. W. F. (1967). Phylogenetic analysis: Models and estimation procedures. Evolution, 21, 550-570.

Chang, H. (2011). The philosophical grammar of scientific practice. International Studies in the Philosophy of Science, 25, 205-221.

Chomsky, N. (1980). Rules and representation. New York: Columbia University Press.

Craver, C. F. (2007). Explaining the brain: Mechanisms and the mosaic unity of neuroscience. Oxford: Oxford University Press.

Craver, C. F., \& Darden, L. (2005). Introduction. Studies in History and Philosophy of Science Part C: Studies in History and Philosophy of Biological and Biomedical Sciences, 36, 233-244.

Creager, A., Lunbeck, E., \& Wise, N. (Eds.). (2007). Science without laws: Model systems, cases, exemplary narratives. Durham: Duke University Press.

Crombie, A. C. (1981). Philosophical presuppositions and shifting interpretations of Galileo. In J. Hintikka, D. Gruender, \& E. Agazzi (Eds.). Theory change, ancient axiomatics, and Galileo's methodology: Proceedings of the 1978 Pisa conference on the history and philosophy of science (Vol. 1, pp. 271-286). Dordrecht, Holland: D. Reidel Publishing Co.

Crombie, A. C. (1988). Designed in the mind: Western visions of science, nature and humankind. History of Science, 26, 1-12.

Crombie, A. C. (1994). Styles of scientific thinking in the European tradition (Vol. Vols. 1-3). London: Duckworth.

Crombie, A. C. (1996). Commitments and styles of European scientific thinking. Theoria, 11, 65-76.

Darwin, C. R. (1964). On the origin of species by means of natural selection or the preservation of favoured races in the struggle for life. Cambridge, MA: Harvard University Press (First published 1859 by John Murray, London).

Davidson, A. (2001). The emergence of sexuality: Historical epistemology and the formation of concepts. Cambridge, MA: Harvard University Press. 
Davidson, D. (1973). On the very idea of a conceptual scheme. Proceedings and Addresses of the American Philosophical Association, 47, 5-20.

Doolittle, W. F. (1999). Phylogenetic classification and the universal tree. Science, 284, 2124-2128.

Doolittle, W. F., \& Bapteste, E. (2007). Pattern pluralism and the tree of life hypothesis. Proceedings of the National Academy of Sciences (USA), 104, 2043-2049.

Downes, S. (1992). The importance of models in theorizing: A deflationary semantic view. PSA: Proceedings of the 1992 Biennial Meeting of the philosophy of science association (Vol. 1, pp. 142-153). Chicago: University of Chicago Press [Contributed papers].

Edwards, A. W. F., \& Cavalli-Sforza, L. L. (1964). Reconstruction of evolutionary trees In V. H. Heywood \& M. McNeill (Eds.), Phenetic and phylogenetic classification (pp. 67-76). London: McNeill.

Elwick, J. (2007). Styles of reasoning in British life sciences: Shared assumptions, 1820 1858. London: Pickering \& Chatto.

Ereshefsky, M. (2001). The poverty of the Linnaean hierarchy: A philosophical study of biological taxonomy. Cambridge: Cambridge University Press.

Felsenstein, J. (2004). Inferring phylogenies. Sunderland, MA: Sinauer Associates Inc.

Forrester, J. (1996). If $p$, then what? Thinking in cases. History of the Human Sciences, $9,1-25$.

French, S., \& Ladyman, J. (1997). Superconductivity and structures: Revisiting the London account. Studies in History and Philosophy of Science Part B: Studies in History and Philosophy of Modern Physics, 28, 363-393.

French, S., \& Ladyman, J. (1999). Reinflating the semantic approach. International Studies in the Philosophy of Science, 13, 103-121.

Frigg, R. (2010). Fiction and scientific representation. In R. Frigg \& M. C. Hunter (Eds.). Beyond Mimesis and Convention, Boston Studies in the Philosophy of Science (Vol. 262, pp. 97-138). Dordrecht: Springer Verlag.

Galison, P. (1988). History, philosophy, and the central metaphor. Science in Context, 2, 197-212.

Galison, P. (1997). Image and logic: A material culture of microphysics. Chicago: University of Chicago Press.

Godfrey-Smith, P. (2003). Theory and reality: An introduction to the philosophy of science. Chicago: University of Chicago Press.

Gould, S. J. (1996). The mismeasure of man. New York: W. W. Norton \& Co. (First published 1981)

Gould, S. J. (1987). Time's arrow, time's cycle: Myth and metaphor in the discovery of geological time. Cambridge, MA: Harvard University Press.

Griffiths, G. C. D. (1974). On the foundations of biological systematics. Acta Biotheoretica, 13, 85-131.

Hacking, I. (1975). Why does language matter to philosophy? Cambridge: Cambridge University Press.

Hacking, I. (1981). Introduction. In I. Hacking (Ed.), Scientific revolutions (pp. 1-5) Oxford: Oxford University Press.

Hacking, I. (1983). Representing and intervening: Introductory topics in the philosophy of natural science. Cambridge: Cambridge University Press.

Hacking, I. (1985). Styles of scientific reasoning. In J. Rajchman \& C. West (Eds.) Post-analytical philosophy (pp. 145-165). New York: Columbia University Press

Hacking, I. (1990). The Taming of Chance. Cambridge: Cambridge University Press.

Hacking, I. (1992). The self-vindication of the laboratory sciences. In A. Pickering (Ed.), Science as practice and culture (pp. 29-64). Chicago: University of Chicago Press.

Hacking, I. (1994). Styles of scientific thinking or reasoning: A new analytical too for historians and philosophers of the sciences. In K. Gavroglu, J. Christianidis, \& E. Nicolaidis (Eds.), Trends in the historiography of science (pp. 31-48) Dordrecht: Kluwer Academic Publishers.

Hacking, I. (2002a). Historical ontology. Cambridge, MA: Cambridge University Press

Hacking, I. (2002b). Language, truth, and reason. In M. Hollis \& S. Lukes (Eds.), Rationality and relativism (pp. 48-66). Oxford: Blackwell. 1982; reprinted in Hacking 2002a, pp. 159-177.

Hacking, I. (2002c). 'Style' for historians and philosophers. Studies in History and Philosophy of Science 23, 1-20; reprinted in Hacking 2002a, 178-199.

Hacking, I. (2006). The emergence of probability: A philosophical study of early ideas about probability, induction and statistical inference (2nd ed.). Cambridge: Cambridge University Press. (First published 1975).

Hacking, I. (2009). Scientific reason. Taipei: National Taiwan University Press.

Hennig, W. (1965). Phylogenetic systematics. Annual Review of Entomology, 10 , 97-116.

Hennig, W. (1966). Phylogenetic systematics. [Translation by D.D. Davis and R Zangerl of Grundzüge einer Theorie der phylogenetischen Systematik, Berlin: Deutscher Zentralverlag, 1950]. Urbana, IL: University of Illinois Press.

Hesse, M. (1963). Models and analogies in science. London: Sheed and Ward.

Hull, D. (1988). Science as a process. Chicago: University of Chicago Press.

Huson, D. H., Rupp, R., \& Scornavacca, C. (2010). Phylogenetic networks: Concepts, algorithms and applications. Cambridge: Cambridge University Press.

Husserl, E. (1970). The Crisis of European Sciences and Transcendental Phenomenology. [Translation by Northwestern University Press of Die Krisis der europäischen Wissenschaften und die transzendentale Phänomenologie: Eine Einleitung in die phänomenologische Philosophie, Walter Biemel (Ed.), The Hague: Martinus Nijhoff, 1954]. Evanston, IL: Northwestern University Press.

Kuhn, T. (1970). The structure of scientific revolutions (2nd ed.). Chicago: University of Chicago Press (First published 1962).

Kuhn, T. (1977). Second thoughts on paradigms. In F. Suppe (Ed.), The structure of scientific theories (2nd ed., pp. 459-482). Urbana, IL: University of Illinois Press.
Kusch, M. (2010). Hacking's historical epistemology: A critique of styles of reasoning. Studies in History and Philosophy of Science Part A, 41, 158-173.

Kwa, C. (2011). Styles of knowing: A new history of science from ancient times to the present. Pittsburgh, PA: University of Pittsburgh Press.

Ladyman, J., Bueno, O., Suárez, M., \& van Fraassen, B. (2011). Scientific representation: A long journey from pragmatics to pragmatics. Metascience, 20(3), 417-442.

Laubichler, M., \& Müller, G. (Eds.). (2007). Modeling biology: Structures, behaviors, evolution. Cambridge, MA: MIT Press.

Linnaeus, C. (1735). Systema naturæ, sive regna tria naturæ systematice proposita per classes, ordines, genera, \& species. Lugduni Batavorum [Leiden]: Theodorum Haak.

Linnaeus, C. 1758 (Vol 1), 1759 (Vol 2). Systema naturæ per regna tria naturæ, secundum classes, ordines, genera, species, cum characteribus, differentiis, synonymis, locis. Editio decima, reformata. Holmiæ [Stockholm]: Laurentii Salvii.

Lloyd, G. E. R. (1961). The development of Aristotle's theory of the classification of animals. Phronesis, 6, 59-81.

Lovejoy, A. O. (1936). The great chain of being: A study of the history of an idea. Cambridge, MA: Harvard University Press.

Maienschein, J. (1991). Epistemic styles in German and American embryology. Science in Context, 4, 407-427.

Mancosu, P. (2010). Mathematical style. In E. N. Zalta (Ed.), The Stanford Encyclopedia of Philosophy (Spring 2010 Edition). Retrieved July 12, 2011, from: http://plato.stanford.edu/archives/spr2010/entries/mathematical-style.

Masterman, M. (1970). The nature of a paradigm. In I. Lakatos \& A. Musgrave (Eds.), Criticism and the growth of knowledge (pp. 59-89). Cambridge: Cambridge University Press.

McMullin, E. (1985). Galilean idealization. Studies in History and Philosophy of Science Part A, 16, 247-273.

McShea, D. (1991). Complexity and evolution: What everybody knows. Biology and Philosophy, 6, 303-324.

Michener, C. D., \& Sokal, R. S. (1957). A quantitative approach to a problem in classification. Evolution, 11, 130-162.

Minsky, M. L. (1965). Matter, mind and models. Proc Intl Federation of Information Processing Congress, 1, 45-49.

Mishler, B. D. (2000). Deep phylogenetic relationships among "plants" and their implications for classification. Taxon, 49, 661-683.

Mishler, B. D. (2009). Three centuries of paradigm changes in biological classification: Is the end in sight? Taxon, 58, 61-67.

Müller-Wille, S. (2007). Collection and collation: Theory and practice of Linnaean botany. Studies in History and Philosophy of Science Part C: Studies in History and Philosophy of Biological and Biomedical Sciences, 38, 541-562.

Pickstone, J. V. (2000). Ways of knowing: A new history of science, technology and medicine. Chicago: University of Chicago Press.

Popper, K. (1996). The myth of the framework. In M. A. Notturno (Ed.), The myth of the framework: In defence of science and rationality (pp. 33-64). Abingdon, Oxon: Routledge.

Rieppel, O. (1988). Fundamentals of comparative biology. Basel, Switzerland: Birkhauser Verlag AG

Rieppel, O. (2010). The series, the network, and the tree: Changing metaphors of order in nature. Biology and Philosophy, 25, 475-496.

Rouse, J. (2002). How scientific practices matter: Reclaiming philosophical naturalism. Chicago: University of Chicago Press.

Roux, W. (1905). Die Entwicklungsmechanik der Organismen. ein neuer Zweig der biologischen Wissenschaft. Leipzig: W. Engelmann.

Shapin, S., \& Schaffer, S. (1985). Leviathan and the air-pump: Hobbes, Boyle, and the experimental life. Princeton: Princeton University Press.

Sloan, P. R. (1972). John Locke, John Ray, and the problem of the natural system. Journal of the History of Biology, 5, 1-53.

Sober, E. (1988). Reconstructing the past. Parsimony, evolution, and inference. Cambridge, MA: MIT Press.

Sober, E. (2004). The contest between parsimony and likelihood. Systematic Biology, $53,644-653$

Sokal, R. R., \& Michener, C. D. (1958). A statistical method for evaluating systematic relationships. University of Kansas Science Bulletin, 38, 1409-1438.

Stevens, P. F. (1994). The development of biological systematics: Antoine-Laurent de Jussieu, nature, and the natural system. New York: Columbia University Press.

Suárez, M., \& Cartwright, N. (2008). Theories: Tools versus models. Studies in History and Philosophy of Modern Physics, 39, 62-81.

Suppe, F. (Ed.). (1977a). The structure of scientific theories (2nd ed.). Urbana, IL: University of Illinois Press.

Suppe, F. (1977b). The search for philosophic understanding of scientific theories. In F. Suppe (Ed.), The structure of scientific theories (2nd ed., pp. 3-241). Urbana, IL: University of Illinois Press.

Suppe, F. (1989). The semantic conception of theories and scientific realism. Urbana, IL: University of Illinois Press.

Suppes, P. (1960). A comparison of the meaning and uses of models in mathematics and the empirical sciences. Synthese, 12, 287-301.

Suppes, P. (1962). Models of data. In E. Nagel, P. Suppes, \& A. Tarski (Eds.), Logic, methodology, and philosophy of science: Proceedings of the 1960 International Congress (pp. 252-261). Stanford, CA: Stanford University Press.

van Fraassen, B. (1970). On the extension of Beth's semantics of physical theories. Philosophy of Science, 37, 325-339.

van Fraassen, B. (1980). The scientific image. Oxford: Oxford University Press. van Fraassen, B. (1989). Laws and symmetry. Oxford: Oxford University Press. 
van Fraassen, B. (2008). Scientific representation: Paradoxes of perspective. Oxford: Oxford University Press.

Vicedo, M. (1995). Scientific styles: Toward some common ground in the history, philosophy, and sociology of science. Perspectives on Science, 3, 231-254.

Weinberg, S. (1976). The forces of nature. Bulletin of the American Academy of Arts and Sciences, 29, 13-29.

Weisberg, M. (2007). Who is a modeler? British Journal for the Philosophy of Science, $58,207-233$.

Williams, B. (2004). Truth and truthfulness: An essay in genealogy. Princeton, NJ: Princeton University Press.

Wilson, R. A., \& Craver, C. F. (2006). Realization. In P. Thagard (Ed.), Elsevier handbook of the philosophy of psychology and cognitive science (pp. 81-104). Dordrecht: Elsevier.

Wimsatt, W. C. (2007). Re-engineering philosophy for limited beings: Piecewise approximations to reality. Cambridge, MA: Harvard University Press.

Winsberg, E. (2010). Science in the age of computer simulation. Chicago: University of Chicago Press.

Winther, R. G. (2006). Parts and theories in compositional biology. Biology and Philosophy, 21, 471-499.

Winther, R. G. (2011a). Part-whole science. Synthese, 178, 397-427.
Winther, R.G. (2011b). Una revisión crítica de los estilos de investigación científica: Teoría, práctica y estilos. In S. Martínez, X. Huang, \& G. Guillaumin (Eds.), Historia, prácticas y estilos en la filosofía de la ciencia. Hacia una epistemología plural (pp. 259-287). Mexico City: Universidad Autónoma Metropolitana Mexico City (in Spanish).

Winther, R. G. (2012). Mathematical modeling in biology: Philosophy and pragmatics. Frontiers in Plant Evolution and Development, 3, article 102, 1-3. Open Access Publication: <http://www.frontiersin.org/Plant_Evolution_and_ Development/10.3389/fpls.2012.00102/full>.

Winther, R. G. (in press). Evo-devo as a trading zone. In A. Love (Ed.) Conceptual Change in Biology: Scientific and Philosophical Perspectives on Evolution and Developmen, Boston Studies in the Philosophy of Science. Dordrecht: Springer Verlag.

Wisan, W. L. (1981). Galileo and the emergence of a new scientific style. In J Hintikka, D. Gruender, \& E. Agazzi (Eds.). Theory change, ancient axiomatics, and Galileo's methodology: Proceedings of the 1978 Pis a conference on the history and philosophy of science (Vol. 1, pp. 311-339). Dordrecht: D. Reidel Publishing Co.

Woese, C. R. (2000). Interpreting the universal phylogenetic tree. Proceedings of the National Academy of Sciences (USA), 97, 8392-8396. 